\title{
The Need to Distinguish Between Quantity and Quality in Research on Parental Involvement: The Example of Parental Help With Homework
}

\section{Sandra Moroni, Hanna Dumont, Ulrich Trautwein, Alois Niggli \& Franz Baeriswyl}

To cite this article: Sandra Moroni, Hanna Dumont, Ulrich Trautwein, Alois Niggli \& Franz Baeriswyl (2015) The Need to Distinguish Between Quantity and Quality in Research on Parental Involvement: The Example of Parental Help With Homework, The Journal of Educational Research, 108:5, 417-431, DOI: 10.1080/00220671.2014.901283

To link to this article: http://dx.doi.org/10.1080/00220671.2014.901283

曲 Published online: 15 Jul 2015.

Submit your article to this journal $₫$

Џ Article views: 410

Q View related articles $\asymp$

View Crossmark data ¿ 


\section{The Need to Distinguish Between Quantity and Quality in Research on Parental Involvement: The Example of Parental Help With Homework}

\author{
SAMBR M \\ University of Teacher Education Bern, Switzerland \\ HANNA DUMONT \\ German Institute for International Educational Research, \\ Germany \\ ULRICH TRAUTWEIN \\ University of Tübingen, Germany
}

\section{ALOIS NIGGLI}

University of Teacher Education Fribourg, Switzerland

FRANZ BAERISWYL

University of Fribourg, Switzerland

\begin{abstract}
Parental involvement research has greatly expanded over the past decade, but findings are mixed, reflecting in part the conceptual and methodological limitations of many studies. On the basis of longitudinal questionnaire data from 1,685 sixth-grade students, the authors studied parental help with homework because it is the most common and most controversial type of parental involvement. Distinguishing between the quantity and quality of parental homework involvement, the research shows that completely different conclusions about the effectiveness of parental homework involvement will be reached if its quantity is assessed instead of its quality: How often parents helped with homework was negatively associated with the development of achievement, whereas homework help that was perceived as supportive had positive predictive effects, and homework help perceived as intrusive had negative effects. Moreover, the results show that effect sizes would be overestimated if students' prior achievement and family background were not controlled.
\end{abstract}

Keywords: academic achievement, family background, homework, parental involvement

I $\mathrm{n}$ recent years, interest in parental involvement in both educational policy and educational research has increased. It is widely believed that parents' involvement in their children's academic life has positive effects on children's academic achievement. Therefore, it is not surprising that the promotion of parental involvement has featured prominently in educational policies in recent years (No Child Left Behind Act of 2001, 2002) and that a number of meta-analyses have been published in the last decade showing that parental involvement may indeed have positive effects on children's academic development
(Fan \& Chen, 2001; Hill \& Tyson, 2009; Jeynes, 2003, $2005,2007,2012)$. However, despite the number of studies on parental involvement, there is still no clear consensus of how strong its effects are and whether parental involvement is always a good thing (Pomerantz, Moorman, \& Litwack, 2007).

In the present article, we argue that this lack of consensus is to a large degree due to conceptual weaknesses in the research on parental involvement. More specifically, some studies have used a global measure of parental involvement, combining different parental behaviors such as parents' attendance at school activities, parental help in preparing for tests, and parenting styles. Even more studies have focused on the quantity or frequency of parental involvement instead of studying the way in which parents become involved, that is, the quality of parental involvement. Moreover, in our view, many studies also suffer from methodological weaknesses. Only a small percentage of longitudinal studies have adequately controlled for students' prior academic performance when analyzing the effects of parental involvement. Similarly, the socioeconomic background of parents is oftentimes not taken into account, which may further bias the results.

The goal of the present study was thus to demonstrate how the conclusions about the effectiveness of parental involvement can be changed by the way in which parental involvement is measured and conceptualized as well as the

Address correspondence to Sandra Moroni, University of Teacher Education Bern, Fabrikstrasse 8, 3012 Bern, Switzerland. (E-mail: sandra.mornoi@phbern.ch) 
inclusion of control variables. We did so by focusing on the most common type of parental involvement: parental help with homework. Homework is an important part not only of students' but also of parents' daily lives, and it can be viewed as the setting in which home and school intersect most closely. Another reason for focusing on the example of parental help with homework is the fact that this is the most controversial type of parental involvement. That is, research has shown that homework help may have not only positive but also detrimental effects on students' academic development (H. Cooper, Lindsay, \& Nye, 2000; Desimone, 1999; Pomerantz, Wang, \& Ng, 2005; Xu, 2004). In line with these findings, Hill and Tyson (2009) reported in their meta-analysis that homework help was the only type of involvement that was not consistently related to academic achievement. Similarly, in a metaanalysis by Patall, Cooper, and Robinson (2008), focusing only on parental homework involvement, the authors concluded that it has "at best a slightly positive overall impact on achievement" (p. 1062). In our study, we made a fundamental distinction between the quantity and quality of parental involvement in homework and demonstrate the need to use multidimensional measures in order to come to consistent conclusions about the effectiveness of parental involvement. Moreover, we used students' prior academic achievement and several indicators of family background as control variables to demonstrate how neglecting these variables may bias the results.

\section{Parental Involvement as a Multidimensional Construct}

Even though the amount of empirical research on parental involvement has increased considerably over the last decade, there is still no uniform definition or conceptualization of the construct. More than 25 years ago, Fehrmann, Keith, and Reimers (1987) pointed out that

parental involvement is by no means a unitary construct. Researchers have used the term "parental involvement" to refer to substantially different types of involvement by parents, and have likewise used different terms to refer to essentially the same type of parental involvement. (p. 330)

Surprisingly, not much has changed since then. Jeynes (2003) wrote that parental involvement is "a vague term that can mean countless different things to different people" (p. 204), and very recently, Karbach, Gottschling, Spengler, Hegewald, and Spinath (2013) stated that "the term has been loosely applied to a variety of activities and the parental behavior subsumed under the construct of PI [parental involvement] has been very heterogeneous" (p. 44). It can be assumed that this variability has contributed to many of the diverse and oftentimes inconsistent findings regarding the effectiveness of parental involvement in improving students' academic achievement.

Because of this heterogeneous conceptualization of parental involvement, several researchers have suggested classifications of the different types of parental involvement. For instance, Grolnick and Slowiaczek (1994) distinguished between behavioral involvement, personal involvement, and cognitive/intellectual involvement. Epstein (1992), however, suggested six different dimensions: parenting, communicating, volunteering, learning at home, decision making, and collaborating within the community. The most common distinction is the classification of home-based and school-based involvement (Deslandes \& Bertrand, 2005; Green \& Walker, 2007; Hoover-Dempsey \& Sandler, 1997; Pomerantz et al., 2007), with homebased involvement referring to parents' practices related to their child's school life taking place outside of school, and school-based involvement referring to practices involving direct contact between parents and schools. Whatever categorization researchers choose to use, the important thing is that they account for the multidimensional nature of parental involvement and measure each dimension separately. Although most studies have done so (Fan, 2001; Grolnick \& Slowiaczek, 1994; Hill, 2008; Karbach et al., 2013; Shumow, 2010; Waanders, Mendez, \& Downer, 2007; Wild \& Remy, 2002; Xu, Kushner Benson, MudreyCamino, \& Steiner, 2010), there are still studies that have collapsed very heterogeneous aspects of parental involvement into one global measure (e.g., Hawes \& Plourde, 2005; Hill et al., 2004; Pelegrina, García-Linares, \& Casanovam, 2003).

In addition to the multidimensional nature of parental involvement and based on the assumption that more involvement may not always be beneficial, several researchers have suggested that the quantity and quality of parental involvement be distinguished (Balli, Wedman, \& Demo, 1997; Grolnick, 2003; Hoover-Dempsey et al., 2005; Hyde, Else-Quest, Alibali, Knuth, \& Romberg, 2006; Pomerantz et al., 2007). This was nicely summarized by Pomerantz et al. (2007), who stated that "a focus on how parents become involved in children's schooling underscores the importance of studying the quality of parents' involvement rather than simply the extent of parents' involvement" (p. 398). Unfortunately, the majority of the studies on parental involvement have continued to use "a relatively crude measure of the quantity of involvement," as Hyde et al. (2006, p. 137) pointed out. However, it is possible to come to completely different evaluations of the effectiveness of parental involvement depending on whether the quantity or the quality is examined.

\section{Previous Studies on the Effectiveness of Parental Involvement}

On the basis of 25 studies, the first meta-analysis on parental involvement (Fan \& Chen, 2001) found a small to moderate association with students' academic achievement of $r=.25$. The strongest associations were observed for studies that focused on parental aspirations, the weakest for studies that investigated home supervision. Jeynes $(2003,2005,2007)$ also conducted three meta-analyses on 
the effectiveness of parental involvement, with each metaanalysis focusing on a particular population. The first (Jeynes, 2003), which focused on minority students and analyzed 21 studies, found a positive effect of parental involvement of at least $d=0.20$, which varied depending on the minority group as well as the parental involvement dimension. The target population of the other two metaanalyses was urban students. The 2005 meta-analysis focused on elementary school students across 41 studies, and the one published in 2007 analyzed secondary school children across 52 studies. For the elementary school children, Jeynes (2005) found an average effect of parental involvement on academic achievement of $d=0.74$, and for the secondary school children of $d=0.46$ (Jeynes, 2007). In both meta-analyses, the highest associations were observed for parents' expectations and the lowest for homework supervision. The most recent meta-analysis on the effects of parental involvement was conducted by Hill and Tyson (2009). The authors focused on middle school students and investigated 50 different studies. They distinguished between home-based involvement, school-based involvement, and academic socialization. The strongest association with students' academic achievement-with a weighted correlation of $r=.39$-was observed for academic socialization, which included aspects such as parental aspirations and communication between parents and students. School-based involvement also served as a predictor of students' academic achievement (weighted correlation of $r=.19$ ). No effect was found for home-based involvement; however, in-depth analyses that examined different types of home-based involvement revealed that parental homework involvement was the only aspect that showed a negative association and thus cancelled out the positive effects of other activities at home.

Based on these meta-analyses as well as on more recent studies (Fan \& Williams, 2010; Karbach et al., 2013; Mägi, Lerkkanen, Poikkeus, Rasku-Puttonenn, \& Nurmi, 2011; Xu et al., 2010; You \& Nguyen, 2011), it can be concluded that parental involvement has an effect on students' academic achievement. However, because the meta-analyses used different methods to combine the results and to calculate the effect sizes, it is hard to draw more specific conclusions. The strongest associations were revealed for parents' expectations and aspirations, whereas parental homework involvement - the focus of the present study - was shown to have only weak associations. Should we therefore conclude that parents' expectations matter more than their actual help in the homework process? We believe close attention needs to be paid to the conceptual and methodological implementation of a study to come to a valid conclusion about the effect of parental involvement.

Most of the studies included in the meta-analyses measured the quantity or frequency of parental involvement, but only a few studies looked at how parents became involved. Moreover, as far as we can determine, most of the studies were cross-sectional and did not control for students' prior achievement or their family background. However, if wanting to study the incremental effect of parental involvement on students' academic achievement, which is what policy makers are usually interested in, it is necessary to account for students' prior achievement. Previous studies have shown that parental involvement does not only affect students' achievement, but is also affected by it. For instance, when children are not doing well at school, parents' involvement at home tends to be intrusive and controlling (Ng, Kenney-Benson, \& Pomerantz, 2004; Niggli, Trautwein, Schnyder, Lüdtke, \& Neumann, 2007). Therefore, cross-sectional studies with only one measure of academic achievement cannot disentangle the effect that parental involvement has on students' achievement and the effect that students' achievement has on parental involvement. Similarly, it is also important to control for students' family background to get an accurate estimate of the effectiveness of parental involvement on students' achievement, as previous research has shown that family background variables have a major influence on students' achievement (McLoyd, 1998) and that family background variables are also associated with parents' involvement (e.g., C. E. Cooper, Crosnoe, Suizzo, \& Pituch, 2010; Englund, Luckner, Whaley, \& Egeland, 2004; Turney \& Kao, 2009). For instance, it is well known that parental aspirations are strongly associated with parents' socioeconomic background (Davis-Kean, 2005; Englund et al., 2004; Suizzo \& Stapleton, 2007). Thus, it could be the case that the strong associations that were observed for this dimension of parental involvement are driven mainly by a confounding third variable-parents' socioeconomic background. Similarly, the conclusions that could be drawn about the usefulness of parental homework involvement on the basis of the meta-analyses may not be accurate because many studies did not include prior achievement and family background as control variables.

\section{Parental Involvement in Homework}

As mentioned above, parental involvement in homework is the most common but also the most controversial type of parental involvement. This became evident when we summarized the findings from the meta-analyses on parental involvement. The following section provides an overview of the empirical evidence on the effectiveness of parental homework involvement.

Not surprisingly, with regard to the quantity of parental involvement in homework, the results of empirical studies vary greatly. Xu (2004), for example, reported a positive association between parental homework involvement and students' homework behavior. However, researchers including H. Cooper et al. (2000), Desimone (1999), Hill and Tyson (2009), Pomerantz et al. (2005), and Singh, Bickley, Trivette, and Keith (1995), to mention a few, found negative associations. Other authors, again, have suggested that parental homework involvement has no effect at all on 
students' academic achievement (Levin et al., 1997). In their synthesis of previous research on parental homework involvement, Patall et al. (2008) concluded that parental involvement in homework was only weakly associated with students' academic achievement. However, as already pointed out previously for parental involvement in general, the majority of previous studies on parental homework involvement have also considered only its quantity. There is reason to believe that the use of the quantity of parental homework involvement has contributed to the conclusion that parental help with homework does not make a difference in students' academic achievement.

When the quality of parental involvement in homework is considered, a much more consistent pattern of its relation to academic achievement emerges. When parents' homework involvement has been characterized by support of autonomy, a good structure, positive affect, positive beliefs, and emotional support, positive associations with academic achievement have been revealed (H. Cooper et al., 2000; Dumont, Trautwein, Lüdtke, Neumann, Niggli, \& Schnyder, 2012; Grolnick \& Ryan, 1989; Knollmann \& Wild, 2007; Pomerantz et al., 2007; Pomerantz et al., 2005). Negative associations with academic achievement have been found when parents are not well versed in a subject; when their homework involvement is developmentally inappropriate, confusing to the child, inconsistent with school expectations, controlling, or intrusive; or when there are negative parental emotions (Balli, 1998; Christenson, 2004; H. Cooper et al., 2000; Desimone, 1999; Dumont, Trautwein, \& Lüdtke, 2012; HooverDempsey \& Sandler, 1997; Ng et al., 2004; Pomerantz et al., 2005). Many of these studies were conducted on the bases of the self-determination theory by Deci and Ryan (1985, 1987), which postulates three basic human needs: the need for competence, the need for autonomy, and the need for psychological relatedness. These innate needs are facilitated, when parental behavior is characterized by autonomy support, interpersonal involvement and structure and undermined when parental behavior is controlling, that is characterized by pressure, intrusiveness and dominance (Grolnick, 2003, 2009; Grolnick, Deci, \& Ryan, 1997).

Taken together, there is reason to believe that it is necessary to look at how parents help with homework instead of how often they get involved in the homework process. However, to our knowledge, the effects of the quantity versus the quality of parental homework involvement have not been investigated together in one single study.

\section{The Present Study}

Although a large number of authors have criticized the heterogeneous conceptualization and poor measurement of parental involvement (e.g., Fan \& Chen, 2001; Gerber \& Wild, 2009; Harris \& Goodall, 2008; Hill \& Tyson, 2009;
Jeynes, 2003), the field still has not overcome some of its conceptual and methodological limitations. With the present study, we wanted to advance research on parental involvement by showing how the results differ depending on the measures and control variables used. To do so, we focused on parental involvement in homework as this has been shown to be the most common and, at the same time, the most controversial type of involvement.

We investigated the effects of parental help with homework on students' academic achievement, distinguishing between its quantity and quality. The quantity measure indicated how often parents helped their children with homework across a time period of 1 week. The quality of parental involvement in homework was measured by two different dimensions informed by self-determination theory (Deci \& Ryan, 1985, 1987) differentiating positive and negative forms of parental involvement with homework, with involvement characterized by autonomy and emotional support on the one hand (hereafter called supportive involvement) and involvement characterized by intrusiveness and control on the other hand (hereafter called intrusive involvement). Given that parental behavior, such as checking children's homework, may be perceived by the child as either supportive or intrusive, we considered the students' response instead of the parents' response or any other objective measure. In fact, previous research has shown that children's interpretations of parental behavior are more strongly related to their development than are parents' actual behaviors (Grolnick, Ryan, \& Deci, 1991; Grolnick \& Slowiaczek, 1994; Hoover-Dempsey et al., 2005; Schaefer, 1965). Hence, children's reports have been commonly used as indicators of parenting quality (Schaefer, 1965).

We hypothesized that the quantity of parental help with homework would not improve students' achievement. Instead, we expected the way parents become involved to matter for students' academic development. In addition, we hypothesized that the effects of parental homework involvement would be larger when prior achievement and students' family background were not controlled for. Using a large and representative sample of students at the beginning of secondary school, these hypotheses were analyzed in a longitudinal structural equation modeling framework (Byrne, 2011) in which we regressed students' academic achievement in Grade 6 on students' prior achievement, their family background and the quantity or the quality of parental homework involvement.

\section{Method}

Sample

The sample used in the present study came from a representative longitudinal multicohort study on the transition process from primary school to secondary school in the German speaking part of the canton of Fribourg, 
Switzerland. This study is currently being conducted at the University of Fribourg in cooperation with the University of Teacher Education Fribourg, Switzerland. Data were collected in Grades 4 and 5 by the University of Teacher Education and in Grades 6 and 9 by the University of Fribourg. The first two measurement points placed special emphasis on reading skills, the last two measurement point focus on the transition process from primary school to secondary school. For the present study, we used data from Grades 5 and 6. Hence, we had data from 1,685 students (48.9\% male) and their parents (1,498 parents responded, indicating a remarkably high participation rate of $88.8 \%$ ). In the school system of Fribourg students attend primary school for 6 years. After the sixth year there is a transition to secondary school, which contains three different tracks. Usually students are 6 years old when entering primary school and 12 years old when entering secondary school. At the first measurement point, the mean age for students was 9.76 years old ( $S D=0.54$ years). Regarding immigration, $13.2 \%$ of the students were from immigrant families (defined as both parents born outside of Switzerland), and $14.8 \%$ indicated that they did not speak German at home. Regarding the educational background of parents, $25.3 \%$ of the parents reported having a college degree or a doctorate, $27.4 \%$ reported having a higher professional education, and $47.3 \%$ reported having a professional education, a degree from an upper secondary specialized school, or a degree from a lower secondary school.

\section{Procedure}

With the exception of the Ein Leseverständnistest für Erst- und Sechstklässler (ELFE) test (prior achievement), which was administered in November of Grade 5 (first measurement point), student data were collected in February and March of Grade 6 (second measurement point). Student questionnaires and the standardized achievement test were administered during regular school hours in intact classrooms by trained research assistants in a morning session. Parent questionnaires were sent home with the children at the first measurement point. The participation was voluntary and parents were asked to give their consent for their children's participation. All participating students and parents were informed about the study's objectives and assured that their data would be used anonymously and for scientific purposes only.

\section{Instruments}

Family background variables. We measured students' family background through multiple indicators in order to account for its multidimensional nature (Murdock, 2000; Sirin, 2005). Students' immigration background was measured using students' and parents' responses regarding which country parents were born in. The information was transformed into a dummy variable, which indicated whether both parents were born in a foreign country $(0=$ no immigration background, $1=$ immigration background). Parents' occupational status was measured with the widely used International Socio-Economic Index of Occupational Status (ISEI; Ganzeboom, De Graaf, Treiman, \& De Leeuw, 1992) with occupational data provided by both students and parents. The higher a person's ISEI score, the higher his or her status. For cases in which scores were available for both the father's and the mother's occupations, the higher score was included in the analyses. The parents' highest educational level was examined separately for the mother and the father. We used the higher education level of the two parents in the analyses. As there were three educational levels, the variable was transformed into two dummy variables representing the lower and the higher educational level, using the intermediate educational level. Number of books possessed by the family, as a proxy for parents' cultural capital (Organization for Economic Coopereation and Development, 2002), was measured via a 7-point Likert-type scale ranging from 0 (no books) to 7 (more than 500 books).

Parental homework involvement. With the student questionnaire, we measured two dimensions of perceived quality of parental homework involvement, that is, supportive involvement (e.g., "If I struggle with my German homework, my parents try to find out what exactly it is I didn't understand"; five items; Cronbach's $\alpha=.77$ ) and intrusive involvement (e.g., "My parents always interfere when I'm doing my homework"; four items; Cronbach's $\alpha=.73$ ). Responses were given on a 5-point Likert-type scale ranging from 1 (completely disagree) to 5 (completely agree). All items on the quality of parental homework involvement were adapted from Wild (1999) and are reported in the Appendix. The two dimensions of parental involvement were specified as latent variables in the analyses. The confirmatory factor analysis showed a satisfactory fit to the data, $\chi^{2}(26, N=1,660)=91.344$, comparative fit index $=.974$, root mean square error of approximation $\leq .039$ $(.30 ; .48)$, standardized root mean square residual $=.027$.

The quantity of parental involvement in homework was measured by the question "In general, how often do your parents help you with your homework?" Responses were given on a 6-point Likert-type scale including 0 (never), 1 (less than once a week), 2 (about once a week), 3 (about twice, three times a week), 4 (about four, five times a week), and 5 (always).

Academic achievement. We used two different indicators for students' academic achievement, our outcome variable: a standardized achievement test in the reading domain as an objective measure of students' achievement and students' grades in German as an achievement measure that has actual relevance for students' school careers. The reading achievement test was part of a school transition exam at the end of elementary school. The content of the 
exam was based on the fifth-and sixth-grade school curriculum. All exam questions were created by secondary school teachers in collaboration with primary school teachers who were not directly involved in the actual school transition. In addition, the exams were validated in different cantons that followed the same curriculum. A secondary school teacher supervised the entire exam. The exams were corrected by two secondary school teachers; when there was disagreement, a third secondary school teacher was consulted. Cronbach's alpha for the test was .62. Students' grades in German were collected at the end of the first semester in the sixth grade via teacher reports. In order to control for students' prior achievement for both reading achievement and grades in German, we used a German achievement test that students took in the fifth grade. The test was based on three subtests (word comprehension, sentence comprehension, and text comprehension) of the battery ELFE 1-6 test (Lenhard \& Schneider, 2006); the subtests were then combined into a single score.

All intercorrelations among the variables used in the present study are presented in Table 1, along with the means and standard deviations.

\section{Statistical Analyses}

In order to address our hypotheses, we specified structural equations models in Mplus 5 (Muthén \& Muthén, 2010). Separate but equivalent models were specified for the two indicators of students' academic achievement, standardized reading achievement test, and German grades. Moreover, we specified equivalent models for the quality of parental involvement (Models a) and the quantity of parental involvement (Models b). In Model 1, students' achievement was regressed on prior achievement, family background, and the quality (Model 1a) and quantity of parental involvement (Model 1b). In Model 2, students' achievement was regressed on family background and quality/quantity of parental involvement without controlling for students' prior achievement. In Model 3, students' achievement was regressed on prior achievement and quality/quantity of parental involvement without controlling for family background. Finally, in Model 4, students' achievement was regressed on quality/quantity of parental involvement without controlling for either prior achievement or family background. In all models, we controlled for sex because studies have reported that parents' involvement in boys' homework is more controlling and intrusive (Bhanot \& Jovanovic, 2005; Niggli et al., 2007). The majority of previous studies have resembled our Model 4b: an estimate of the effect of the quantity of parental help in homework on achievement without controlling for students' prior achievement or family background. In our view, Model 1a represents a conceptually and methodologically sound model to test the effectiveness of parental homework involvement. Due to the nature of our models we were not successful in formally testing the differences of the coefficients between these models, which is why we decided to compare the coefficients descriptively and emphasize the conceptual differences between the models.

As in most studies that have examined students in school settings, students were nested within classes in the present study. Because our research questions targeted the individual level and we were not interested in classroom effects, the multilevel structure (Raudenbush \& Bryk, 2002) was treated as a nuisance factor. To this end, we used the Mplus 5 (Muthén \& Muthén, 2010) type = complex procedure, which automatically adjusts the standard errors of the regression coefficients (for more information, see Muthén \& Satorra, 1995). Due to longitudinal drop out, the percentage of missing values for the questionnaire items ranged from $0.9 \%$ to $14.5 \%$. One exception was the battery ELFE 1-6 test, with $46.6 \%$ missing values. The large amount of missing data was due to the fact that the longitudinal study began with a smaller sample in Grade 5 when the ELFE 1-6 test was administered but was enriched in Grade 6. Therefore, the students who did not participate in the test were a random sample of the overall sample. Multiple imputation was used to deal with missing data, as this-together with the full information maximum likelihood approach - represents the present state of the art in dealing with missing data (Graham, 2009; Schafer \& Graham, 2002). In doing so, five complete data sets were created using the statistical package IBM SPSS statistics 19 . Mplus 5 automatically integrates the five imputed data sets when running the models.

\section{Results}

Descriptive statistics and intercorrelations of all variables considered in the analyses are presented in Table 1 . Inspection of the intercorrelations between the dimensions of parental homework involvement showed that there was no statistically significant correlation between parental support and parental interference $(r=-.04, n s)$, thus confirming that these are two distinct dimensions. With respect to the relation between the quality and the quantity of parental homework involvement, there was a weak positive correlation between parental support and the quantity of parental help $(r=.13, p<.001)$. The correlation between parental interference and the quantity of parental homework involvement was higher $(r=.41$, $p<.001$ ).

We hypothesized that depending on the way parental homework involvement was conceptualized and measured-either the quantity or the quality of parents' involvement-the results regarding the effectiveness of parental homework involvement in improving students' academic achievement would differ. This hypothesis was strongly supported by our data, both for the standardized reading achievement test (Table 2) and for German grades (Table 3). Looking at the quality of parental homework 


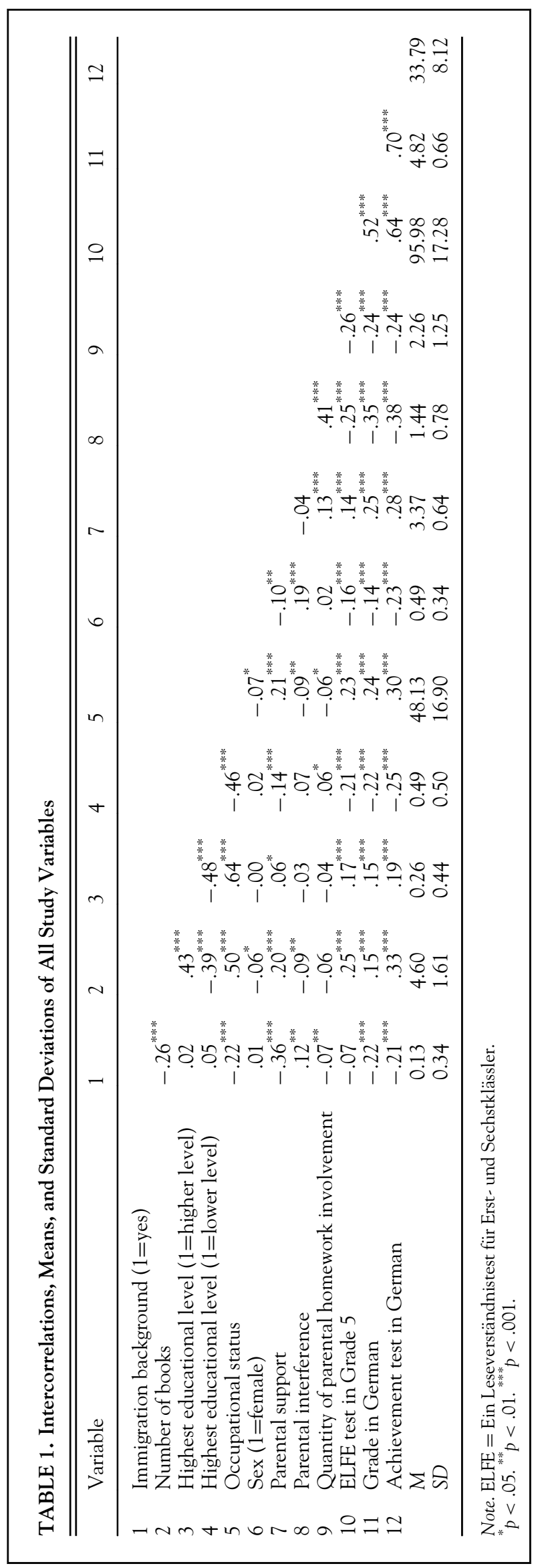


involvement (Model 1a), students who reported more supportive involvement showed higher reading achievement test scores $(\beta=.13, p<.001)$ and higher German grades $(\beta=.12, p<.01)$, whereas students who reported more intrusive involvement showed lower reading achievement test scores $(\beta=-.21, p<.001)$ and lower German grades $(\beta=-.21, p<.001)$ even after controlling for prior achievement and family background variables.

On the other hand, we hypothesized that how often parents helped their children with homework (quantity of parental involvement) would not improve students' achievement. This assumption was supported by the data (see Model 1b). In fact, we even observed a negative association between the quantity of parental homework involvement and students' reading achievement $(\beta=-.10, p<$ $.001)$ and their German grades $(\beta=-.12, p<.001)$ : Students who reported a higher degree of parental involvement in homework showed lower reading performance and lower German grades when controlling for their prior achievement and family background variables. Therefore, if parental homework involvement was measured only by how often parents helped their children with homework, the conclusion would be that parental homework involvement is negatively associated with students' achievement.

Inspection of the variance explained by all predictors revealed that slightly more variance was explained by the quality of parental homework involvement (reading achievement: $R^{2}=.53$; German grades: $R^{2}=.38$ ) than by the quantity of parental homework involvement (reading achievement: $R^{2}=.49$; German grades: $R^{2}=.34$ )

We also hypothesized that the effects of parental homework involvement would differ depending on the control variables that were included in the models. We expected the effects to be larger when prior achievement was not controlled for. This was confirmed by our analyses (see Models 2a and 2b). As for the quality of parental homework involvement, after controlling only for family background variables and not for students' prior achievement, the effect size of supportive involvement increased from Model 1a to Model 2a from $+.13(p<.001)$ to $+.17(p<.001)$ for reading achievement and from $+.12(p<.01)$ to $+.14(p<$ $.001)$ for German grades. The effect size of intrusive involvement even increased from $-.21(p<.001)$ to -.31 $(p<.001)$ for reading achievement and from $-.21(p<$ $.001)$ to $-.30(p<.001)$ for German grades. We found the largest change in effect size when considering quantity of parental homework involvement: It increased from $-.10(p$ $<.001)$ to $-.22(p<.001)$ for reading achievement and from $-.12(p<.001)$ to $-.23(p<.001)$ for German grades. These results suggest that the effect sizes of parental homework involvement would be overestimated if we did not control for prior achievement.

A similar finding was observed for family background as a control variable. We hypothesized that the effects of parental homework involvement would be larger when family background variables were not controlled for. Regarding the quality of parental homework involvement, this assumption was confirmed (see Model 3a). After controlling only for prior achievement and not for family background, the effect size of supportive involvement increased from Model 1a to Model 3a from $+.13(p<.001)$ to $+.19(p<.001)$ regarding reading achievement and from $-.21(p<.001)$ to -.22 ( $p$ $<.001)$ regarding German grades. Regarding intrusive involvement, the effect size slightly increased from $-.21(p$ $<.001)$ to $-.22(p<.001)$ for reading achievement and from $-.21(p<.001)$ to $-.23(p<.001)$ for German grades. However, regarding the quantity of parental homework involvement (see Model 3b), the effect size slightly decreased from $-.10(p<.001)$ to $-.08(p<.001)$ for reading achievement and from $-.12(p<.001)$ to -.11 ( $p$ $<.01)$ for German grades.

In the final models (Models 4a and 4b), we examined the estimates of the effects of parental homework involvement on children's academic achievement when neither prior achievement nor family background was controlled for.

Regarding the quality of parental homework involvement (see Model 4a), the effect size of supportive involvement increased from Model 1a to Model 4a from $+.13(p<.001)$ to $+.25(p<.001)$ for reading achievement and from +.12 $(p<.001)$ to $+.23(p<.001)$ for German grades. Regarding intrusive involvement, the effect size increased from -.21 $(p<.001)$ to $-.34(p<.001)$ for reading achievement and from $-.21(p<.001)$ to $-.33(p<.001)$ for German grades. Regarding the quantity of parental homework involvement, the effect size increased from $-.10(p<.001)$ to $-.24(p<.001)$ for reading achievement and from -.12 $(p<.001)$ to $-.23(p<.001)$ for German grades. These results suggest that effect sizes are heavily overestimated when prior achievement and family background variables are not controlled for, as has been the case in the majority of studies on the effectiveness of parental involvement. As we already pointed out, the majority of previous studies have resembled our Model 4b: an estimate of the effect of the quantity of parental help in homework on achievement without controlling for students' prior achievement or family background. The use of such model tests would come to the conclusion that parental involvement in homework has a relatively large negative effect on students' achievement. By contrast, a conceptually and methodologically sound study investigating the quality of parental help and controlling for prior achievement and family background would come to the conclusion that parental homework involvement can be beneficial when it is perceived as supportive, but that it can also be detrimental when children feel that their parents are intruding in the homework process (Model 1a). These two models can be seen as the two ends of a continuum of the findings usually reported in research on parental involvement.

Because it would be likely that there would be an interaction between the quality and the quantity of parental homework involvement-in the sense that frequent parental help may be beneficial only when it is supportive and 


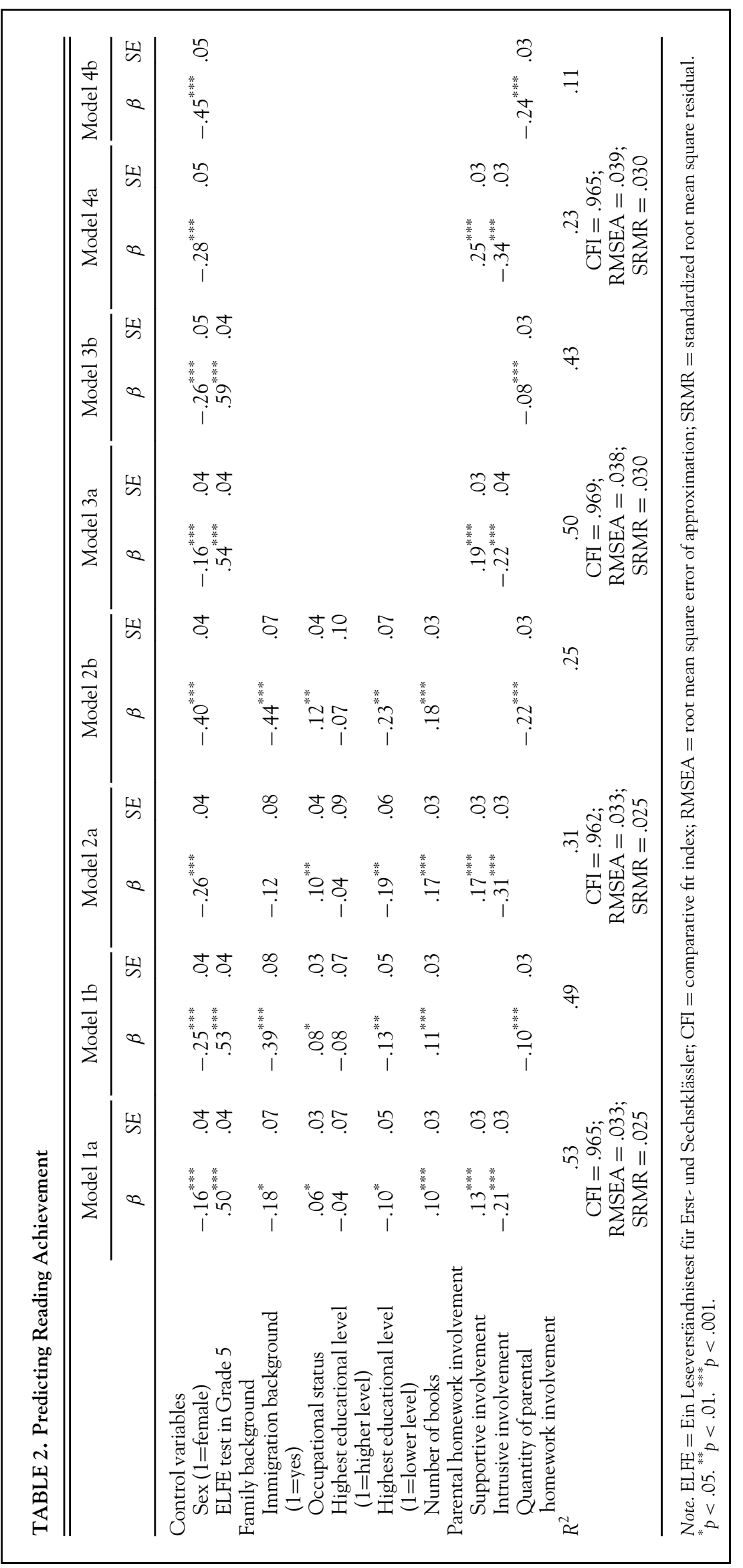




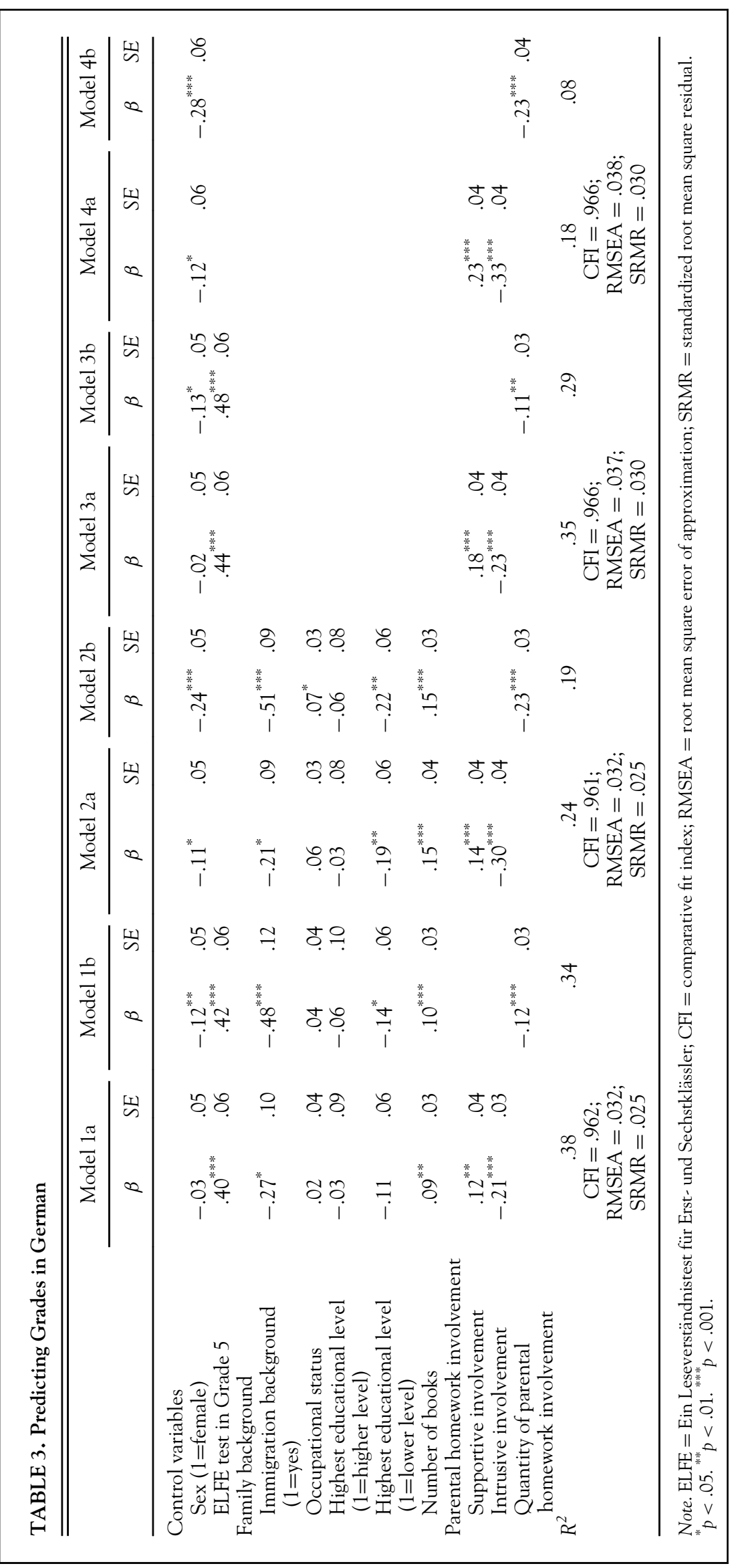


not intrusive-we tested for interaction effects in a further step. However, no significant interaction effects were found in any of the models.

\section{Discussion}

In the present study, we investigated how the results regarding the effectiveness of parental involvement in improving students' academic achievement differ depending on how parental involvement is measured. We did so by focusing on the most common and controversial type of parental involvement-parental help with homework-and made the fundamental distinction between the quantity and the quality of parental homework involvement. In line with our predictions, we were able to demonstrate that different conclusions about the effectiveness of parental homework involvement would be reached by looking at how often parents help their children with homework instead of how they help with homework. We found that the frequency of parental homework help was negatively associated with students' academic achievement even after controlling for their prior achievement. On the other hand, when investigating the quality of parental homework help as perceived by children, a much more differentiated pattern was revealed: When homework involvement was perceived as supportive, it was positively associated with students' achievement, but when parents were perceived as intrusive and controlling in the homework process, their help was negatively associated with students' achievement.

These findings also provide a possible explanation for why the quantity of parental homework involvement has been found to be negatively associated with students' achievement in many previous studies: We observed a high correlation between intrusive involvement and the quantity of parental help, indicating that greater amounts of parental help may be perceived as more intrusive by children. Moreover, our findings are in line with the theoretical predictions of self-determination theory (Deci \& Ryan, 1985, 1987), which states that children's innate needs for competence, autonomy, and psychological relatedness are undermined when parents are controlling and intrusive.

In addition to testing the quantity and quality of parental homework involvement against each other, we also demonstrated how neglecting important control variables can bias the results and thus the conclusions that can be drawn about the effectiveness of parental homework involvement. When students' prior achievement and family background were not controlled for, we found substantially higher beta coefficients for the effects of parental homework involvement.

\section{The Need to Use Multidimensional Measures in Research on Parental Involvement}

What we were able to demonstrate for the case of parental help with homework applies to all research on parental involvement. Although poorly measured parental involvement has been criticized by many researchers, and the need to use multidimensional measures is frequently called for (Fan \& Chen, 2001; Jeynes, 2003; Wild \& Lorenz, 2010), many studies have continued to use global measures of parental involvement (e.g., Hawes \& Plourde, 2005; Hill et al., 2004; Pelegrina et al., 2003), and most studies have continued to focus on how often parents are involved instead of how parents are involved (see meta-analyses by Fan \& Chen, 2001; Hill \& Tyson, 2009; Jeynes, 2003, $2005,2007)$. We believe that our study can advance research on parental involvement by showing the importance of using multidimensional measures and carefully disentangling the different effects that parental involvement can have on children's academic development. Several more recent studies have already moved in this direction (e.g., Karbach et al., 2013; You \& Nguyen, 2011), and it would be valuable to have more studies of this nature in educational research on parental involvement.

Our focus was on parental homework involvement, but how could the quality of parental involvement be measured for other types of parental involvement? Using communication between parents and teachers as an example, in addition to asking whether communication exists, researchers could focus on, for example, what parents and teachers talk about or how parents interact with teachers. Different effects may be found depending on whether parents simply ask the teacher for a report of their child's progress in school or whether the parents intervene by challenging the teacher with regard to the child's grades or by discussing potential future paths for the child. Similarly, in addition to assessing whether children regularly discuss school matters with their parents, researchers could try to get at the contents of parent-child communications. It is possible to measure, for example, how parents communicate their beliefs, their values, and their expectations for children's educational attainment or how they communicate the value of education. For each type of parental involvement, researchers should think carefully about how to operationalize the aspect of quality. In doing so, the data collection method may also make a fundamental difference. For instance, instead of asking students about their parents' involvement as we did in the present study, it is possible also to ask the parents themselves through the use of either questionnaires or interviews. Another possibility would be to observe parent-child interactions and rate the quality of the interaction as has already been done in some studies (e.g., Hyde et al., 2006). However researchers decide to measure the quality of parental involvement, we believe that it is important to disentangle the different dimensions in order to obtain an accurate estimate of the effects of parental involvement on children's academic achievement and to understand the underlying processes and mechanisms of these effects. By looking only at the quantity of parental involvement, one may not fully 
understand how parents influence a child's academic development.

\section{The Need to Control for Prior Achievement and Family Background in Research on Parental Involvement}

In our study, the effects we found for the supportive and intrusive involvement of parents in the homework process after controlling for students' prior achievement and family background may be considered small, and one may argue that these effect sizes are too small to be of practical relevance. Would our findings be considered more relevant if we had found larger effects and had not controlled for students' prior achievement and their family background? There is reason to believe that many policy makers, but also researchers, do not take a study's design into account carefully enough when evaluating its findings. However, in our opinion, given the growing interest and policy relevance of parental involvement, the estimates of its effectiveness should be as accurate as possible. If wanting to study the incremental effect of parental involvement on students' academic achievement, it is necessary to control for students' prior achievement. Moreover, it is crucial to control for family background variables when studying the effects of parental involvement on students' achievement. Hence, in favor of sound methodologies, we may have to accept smaller effect sizes even if this may not be what policy makers want to hear. It is also important to remember that studies on parental involvement are conducted in naturally occurring settings, where a number of nuisance factors are at play (Swann, Chang-Schneider, \& McClarty, 2007). Finally, it is necessary to keep in mind that psychological constructs such as academic achievement are multidetermined (Ahadi \& Diener, 1989). In other words, parental involvement in homework can be assumed to be just one of many factors that influence how students perform in school.

\section{Limitations}

Even though our study had many strengths-most notably, differentiated instruments, a large sample, and a longitudinal framework with a measure of prior achievementseveral limitations need to be noted. First, our findings are restricted to the age group of fifth-and sixth-grade students. Therefore, only conclusions for middle school children can be drawn from our study, and different findings for other developmental levels may be expected. For instance, it has been suggested that parental involvement has a stronger influence on students' achievement for younger children than for middle school students (Englund et al., 2004). Also, school context (e.g., size and complexity of schools), which may be different for elementary and secondary schools, can have an influence on the ways in which parents get involved in their children's academic life (Hill $\&$ Tyson, 2009). Studies therefore need to be transparent and explicit about which developmental level they are focusing on, and future studies should investigate how developmental level influences parental involvement. Second, we had a large number of missing data points for our prior achievement measure. Although the students who did not participate in the test that served as our prior achievement measure were a random sample of the overall sample, and we dealt with this issue using multiple imputation, it would have been more favorable to have a smaller amount of missing data. At the same time, we believe that it is better to use any kind of measure for prior achievement than none. Third, the present study focused on reading achievement and German grades. Although we expect our findings to be similar for other subjects, studies investigating the effects of parental involvement should ideally consider multiple domains. Despite these limitations, we believe that our study has the potential to advance future research on the effectiveness of parental involvement in improving students' academic achievement by having demonstrated how important it is to differentiate between the quantity and quality of parental involvement and by controlling for important variables such as students' prior achievement and family background.

\section{FUNDING}

This research was supported by a grant from the Swiss National Science Foundation (SNSF) to Alois Niggli (Nr. 13DPD3-114174) and a grant from the Ministry of Science, Research, and the Arts Baden-Württemberg to Ulrich Trautwein.

\section{REFERENCES}

Ahadi, S., \& Diener, S. (1989). Multiple determinants and effect size. Journal of Personality and Social Psychology, 56, 398-406. doi:10.1037/ 0022-3514.56.3.398

Balli, S. J. (1998). When mom and dad help: Student reflections on parent involvement with homework. Journal of Research and Development in Education, 31, 142-146.

Balli, S. J., Wedman, J., \& Demo, D. (1997). Family involvement with middle-grades homework: Effects of differential promoting. Journal of Experimental Education, 66, 31-49.

Bhanot, R., \& Jovanovic, J. (2005). Do parents' academic gender stereotypes influence whether they intrude on their children's homework? Sex Roles, 52, 597-607. doi:10.1007/s11199-005-3728-4

Byrne, B. (2011). Structural equation modeling with Mplus: Basic concepts, applications, and programming. Hoboken, NJ: Taylor \& Francis.

Christenson, S. L. (2004). The family-school partnership: An opportunity to promote the learning competence of all students. School Psychology Review, 33, 83-104.

Cooper, C. E., Crosnoe, R., Suizzo, M., \& Pituch, K. A. (2010). Poverty, race, and parental involvement during the transition to elementary school. Journal of Family Issues, 31, 859-883.

Cooper, H., Lindsay, J. J., \& Nye, B. (2000). Homework in the home: How student, family, and parenting-style differences relate to the homework process. Contemporary Educational Psychology, 25, 464-487. doi:10.1006/ceps.1999.1036

Davis-Kean, P. E. (2005). The influence of parent education and family income on child achievement: The indirect role of parental expectations and the home environment. Journal of Family Psychology, 19, 294304.

Deci, E. L., \& Ryan, R. M. (1985). Intrinsic motivation and self-determination in human behavior. New York, NY: Plenum Press. 
Deci, E. L., \& Ryan, R. M. (1987). The support of autonomy and the control of behavior. Journal of Personality and Social Psychology, 53, 10241037. doi:10.1037/0022-3514.53.6.1024

Desimone, L. (1999). Linking parental involvement with student achievement: Do race and income matter? The Journal of Educational Research, 93, 11-30. doi:10.1080/00220679909597625

Deslandes, R., \& Bertrand, R. (2005). Motivation of parental involvement in secondary-level schooling. The Journal of Educational Research, 98, 164-175.

Dumont, H., Trautwein, U., \& Lüdtke, O. (2012). Familiärer Hintergrund und die Qualität elterlicher Hausaufgabenhilfe [Family background and the quality of parental homework involvement]. Psychologie in Erziehung und Unterricht, 59, 109-121.

Dumont, H., Trautwein, U., Lüdtke, O., Neumann, M., Niggli, A., \& Schnyder, I. (2012). Does parental homework involvement mediate the relationship between family background and educational outcomes? Contemporary Educational Psychology, 37, 55-69.

Englund, M. M., Luckner, A. E., Whaley, G. J. L., \& Egeland, B. (2004). Children's achievement in early elementary school: Longitudinal effects of parental involvement, expectations, and quality of assistence. Journal of Educational Psychology, 96, 723-730. doi:10.1037/00220663.96.4.723

Epstein, J. L. (1992). School and family partnerships. In M. Adkin (Ed.), Encyclopedia of educational research (pp. 1139-1151). New York, NY: Macmillan

Fan, X. (2001). Parental involvement and students' academic achievement: A growth modeling analysis. The Journal of Experimental Education, 70, 27-61.

Fan, X., \& Chen, M. (2001). Parental involvement and students' academic achievement: A meta-analysis. Educational Psychology Review, $13,1-22$.

Fan, X., \& Williams, C. M. (2010). The effects of parental involvement on students' academic self-efficacy, engagement and intrinsic motivation. Educational Psychology, 30, 53-74.

Fehrmann, P. G., Keith, T. Z., \& Reimers, T. M. (1987). Home influence on school learning: Direct and indirect effects of parental involvement in high school grades. Journal of Educational Research, 80, 330-337.

Ganzeboom, H. B. G., De Graaf, P. M., Treiman, D. J., \& De Leeuw, J. (1992). A standard international socio-economic index of occupational status. Social Science Research, 21, 1-56. doi:10.1016/0049-089X(92) 90017-B

Gerber, J., \& Wild, E. (2009). Mit wem wird wie zuhause gelernt? Die Hausaufgabenpraxis im Fach Deutsch [With whom students learn at home? Homework practice in German]. Unterrichtswissenschaft, 37, 216-233.

Graham, J. W. (2009). Missing data analysis: Making it work in the real world. Annual Review of Psychology, 60, 549-576.

Green, C. L., \& Walker, J. M. T. (2007). Parents' motivations for involvement in children's education: An empirical test of a theoretical model of parental involvement. Journal of Educational Psychology, 99, 532-544. doi:10.1037/00222-0663.99.3.532

Grolnick, W. S. (2003). The psychology of parental control: How well-meant parenting backfires. Hillsdale, NJ: Lawrence Erlbaum Associates.

Grolnick, W. S. (2009). The role of parents in facilitating autonomous self-regulation for education. Theory and Research in Education, 7, 164173. doi: $10.1177 / 1477878509104321$

Grolnick, W. S., Deci, E. L., \& Ryan, R. M. (1997). Internalization within the family: The self-determination theory perspective. In J. E. Grusec \& L. Kuczynski (Eds.), Parenting and children's internalization of values (pp. 135-161). New York, NY: Wiley.

Grolnick, W. S., \& Ryan, R. M. (1989). Parent styles associated with children's self-regulation and competence in school. Journal of Educational Psychology, 81, 143-154. doi:10.1037//0022-0663.81.2.143

Grolnick, W. S., Ryan, R. M., \& Deci, E. L. (1991). Inner ressources for school achievement: Motivational mediators of children's perceptions of their parents Journal of Educational Psychology, 83, 508-517. doi:10.1037//0022-0663.83.4.508

Grolnick, W. S., \& Slowiaczek, M. L. (1994). Parents' involvement in children's schooling: A multidimensional conceptualization and motivational model. Child Development, 65, 237-252.

Harris, A., \& Goodall, J. (2008). Do parents know they matter? Engaging all parents in learning. Educational Research 50, 277-289. doi:10.1080/ 00131880802309424
Hawes, C. A., \& Plourde, L. A. (2005). Parental involvement and its influence on the reading achievement of 6th grade students. Reading Improvement, 42, 47-57.

Hill, N. E. (2008). Parent involvement. In E. M. Anderman \& L. H. Anderman (Eds.), Psychology of classroom learning (Vol. 2, pp. 669671). Detroit, MI: GALE.

Hill, N. E., Castellino, D. R., Lansford, J. E., Nowlin, P., Dodge, K. A., Bates, J. E., \& Pettit, G. S. (2004). Parent academic involvement as related to school behavior, achievement, and aspirations: Demographic variations across adolescence. Child Development, 75, 1491-1509.

Hill, N. E., \& Tyson, D. F. (2009). Parental involvement in middle school: A meta-analytic assessment of the strategies that promote achievement. Developmental Psychology, 45, 740-763. doi:10.1037/ a0015362

Hoover-Dempsey, K. V., \& Sandler, H. M. (1997). Why do parents become involved in their children's education? Review of Educational Research, 67, 3-42. doi:10.3102/00346543067001003

Hoover-Dempsey, K. V., Walker, J. M. T., Sandler, H. M., Whetsel, D., Green, C. L., Wilkins, A. S., \& Closson, K. (2005). Why do parents become involved? Research findings and implications. The Elementary School Journal, 106, 105-130. doi:10.1086/499194

Hyde, J. S., Else-Quest, N. M., Alibali, M. W., Knuth, E., \& Romberg, T. (2006). Mathematics in the home: Homework practices and motherchild interactions doing mathematics. Journal of Mathematical Behavior, 25, 136-152. doi:10.1016/j.jmathb.2006.02.003

Jeynes, W. H. (2003). A meta-analysis: The effects of parental involvement on minority children's academic achievement. Education and Urban Society, 35, 202-218. doi:10.1177/0013124502239392

Jeynes, W. H. (2005). A meta-analysis of the relation of parental invovlement to urban elementary school student academic achievement. Urban Education, 40, 237-269. doi:10.1177/0042085905274540

Jeynes, W. H. (2007). The relationship between parental involvement and urban secondary school student academic achievement: A metaanalysis. Urban Education, 42, 82-110. doi:10.1177/004208506293818

Jeynes, W. H. (2012). A meta-analysis of the efficacy of different types of parental involvement programs for urban students. Urban Education, 47, 706-742

Karbach, J., Gottschling, J., Spengler, M., Hegewald, K., \& Spinath, F. M. (2013). Parental involvement and general cognitive ability as predictors of domain-specific academic achievement in early adolescence. Learning and Instruction, 23, 43-51.

Knollmann, M., \& Wild, E. (2007). Quality of parental support and students' emotions during homework: Moderating effects of students motivational orientations. European Journal of Psychology of Education, 22, 63-76. doi:10.1007/BF03173689

Lenhard, W., \& Schneider, W. (2006). ELFE 1-6: Ein Leseverständnistest für Erstbis Sechstklässler [ELFE 1-6: A reading comprehension test for students in Grades 1 through 6]. Göttingen, Germany: Hogrefe.

Levin, I., Levy-Shiff, R., Appelbaum-Peled, T., Katz, I., Komar, M., \& Meiran, N. (1997). Antecedents and consequences of maternal involvement in children's homework: A longitudinal analysis. Journal of Applied Developmental Psychology, 18, 207-227. doi:10.1016/S0193. 3973(97)90036-8

Mägi, K., Lerkkanen, M.-K., Poikkeus, A.-M., Rasku-Puttonenn, H., \& Nurmi, J.-E. (2011). The cross-lagged relations between children's academic skill development, task-avoidance, and parental beliefs about success. Learning and Instruction, 21, 664-675.

McLoyd, V. C. (1998). Socioeconomic disadvantage and child development. American Psychologist, 53, 185-204.

Murdock, T. B. (2000). Incorporating economic context into educational psychology: Methodological and conceptual challenges. Educational Psychologist, 35, 113-124. doi:10.1207/S15326985EP3502_5

Muthén, B. O., \& Muthén, L. K. (2010). Mplus user's guide. Los Angeles, CA: Author.

Muthén, B. O., \& Satorra, A. (1995). Complex sample data instructural equation modeling. In P. V. Marsden (Ed.), Sociological Methodology (pp. 267-316). Washington, DC: American Sociological Association.

Ng, F. F.-Y., Kenney-Benson, G. A., \& Pomerantz, E. M. (2004). Children's achievement moderates the effects of mothers' use of control and autonomy support. Child Development, 75, 764-780. doi:10.1111/j.14678624.2004.00705.x

Niggli, A., Trautwein, U., Schnyder, I., Lüdtke, O., \& Neumann, M. (2007). Elterliche Unterstützung kann hilfreich sein, aber Einmischung 
schadet: Familiärer Hintergrund, elterliches Hausaufgabenengagement und Leistungsentwicklung [Parental homework support can be beneficial, but parental intrusion is detrimental: Family background, parental homework supervision, and performance gains]. Psychologie in Erziehung und Unterricht, 54, 1-14.

No Child Left Behind Act of 2001, Pub. L. No. 107-110, § 115, Stat. 1425 (2002).

Organization for Economic Coopereation and Development. (2002). PISA 2000 [Technical report]. Paris, France: Author.

Patall, E. A., Cooper, H., \& Robinson, J. C. (2008). Parent involvement in homework: A research synthesis. Review of Educational Research, 78, 1039-1101. doi:10.3102/0034654308325185

Pelegrina, S., García-Linares, M., \& Casanovam, P. F. (2003). Adolescents and their parents' perceptions about parenting characteristics. Who can better predict the adolescents' academic competence? Journal of Adolescence, 26, 651-665.

Pomerantz, E. M., Moorman, E. A., \& Litwack, S. D. (2007). The how, whom and why of parents' involvement in children's academic lives: More is not always better. Review of Educational Research, 77, 373-410. doi:10.3102/003465430305567

Pomerantz, E. M., Wang, Q., \& Ng, F. F.-Y. (2005). Mothers' affect in the homework context: The importance of staying positive. Developmental Psychology, 41, 414-427. doi:10.1037/0012-1649.41.2.414

Raudenbush, S. W., \& Bryk, A. S. (2002). Hierarchical linear models (2nd ed.). Thousand Oaks, CA: Sage.

Schaefer, E. S. (1965). Children's reports of parental behavior: An inventory. Child Development, 36, 413-424. doi:10.2307/1126465

Schafer, J. L., \& Graham, J. W. (2002). Missing data: Our view of the state of the art. Psychological Methods, 7, 147-177. doi:10.1037/1082989X.7.2.147

Shumow, L. (2010). Parental involvement at home. In D. B. HiattMichael (Ed.), Promising practices to support family involvement in schools (pp. 57-74). Charlotte, N. C.: Inofrmation Age.

Singh, K., Bickley, P. G., Trivette, P., \& Keith, T. Z. (1995). The effects of four components of parental invovlement on eighth-grade student achievement: Structural analysis of NELS-88 data. School Psychology Review, 24, 299-317.

Sirin, S. R. (2005). Socioeconomic status and academic achievement: A meta-analytic review of research. Review of Educational Research, 75, 417-453. doi: $10.3102 / 00346543075003417$

Suizzo, M.-A., \& Stapleton, L. M. (2007). Home-based parental involvement in young children's education: Examining the effects of marental education across U.S. ethnic groups. Educational Psychology, 27, 533556.

Swann, W. B., Chang-Schneider, C., \& McClarty, K. (2007). Do our selfviews matter? Self-concept and self-esteem in everyday life. American Psychologist, 62, 84-94.

Turney, K., \& Kao, G. (2009). Barriers to school involvement: Are immigrant parents disadvantaged? The Journal of Educational Research, 102, 257-271.

Waanders, C., Mendez, J. L., \& Downer, J. T. (2007). Parent characteristics, economic stress and neighborhood context as predictors of parent involvement in preschool children's education. Journal of School Psychology, 45, 619-636.

Wild, E. (1999). Elterliche Erziehung und schulische Lernmotivation [Parenting and students' motivation to learn] (Unpublished habilitation thesis). University of Mannheim, Germany.
Wild, E., \& Lorenz, F. (2010). Elternhaus und Schule [Home and school]. Paderborn, Germany: Schöningh/UTB.

Wild, E., \& Remy, K. (2002). Quantität und Qualität der elterlichen Hausaufgabenbetreuung von Drittklässlern in Mathematik [The quantity and quality of parental help with third graders' mathematics homework]. Zeitschrift für Pädagogik, 45(Suppl.), 276-290.

$\mathrm{Xu}, \mathrm{J}$. (2004). Family help and homework management in urban and rural secondary schools. Teachers College Record, 106, 1786-1803. doi:10.1111/j.1467-9620.2004.00405.x

Xu, J., Kushner Benson, S., Mudrey-Camino, R., \& Steiner, R. (2010). The relationship between parent involvement, self-regulated learning, and reading achievement of fifth graders: A path analysis using the ECLS-K database. Social Psychology of Education, 13, 237-269.

You, S., \& Nguyen, J. (2011). Parents' involvement in adolescents' schooling: A multidimensional conceptualisation and meditational model. Educational Psychology, 31, 547-558.

\section{AUTHORS NOTE}

Sandra Moroni is a Lecturer at the University of Teacher Education Bern, Switzerland. Her research interests include parental involvement, homework, and mentoring in teacher education.

Hanna Dumont is a postdoctoral research scientist at the German Institute for International Educational Research (DIPF), Berlin, Germany. Her research interests include the effects of schools' social and ethnic composition, tracking and ability grouping, parental involvement, and individualized instruction.

Ulrich Trautwein is Professor of Education Sciences at the Hector Research Institute of Education Sci-ences and Psychology and Director of the LEAD Graduate School. His main research interests include educational transitions, the effects of different learning environments on self-concept, interest, and personality development, and the role of self-related cognitions in students' homework behavior.

Alois Niggli is Professor of Didactics at the University of Teacher Education Fribourg, Switzerland. His research interests include mentoring in teacher education, homework, inner differentiation, and reading enhancement in schools and at home.

Franz Baeriswyl is Emeritus Honorary Professor of Didactics and Educational Psychology at the University of Fribourg, Switzerland. His main research topics are transitions in the school system and social inequality, the composition of school grades, and the transition from the vocational education to the professional life. 


\section{Means and Standard Deviations of Parental Homework Involvement}

\begin{tabular}{lll}
\hline Item & M & $S D$
\end{tabular}

Support $(\alpha=.77)$

My parents help me with German if I ask them.

4.351 .10

I can ask my parents any time if I don't understand my German homework.

$\begin{array}{ll}4.51 & 0.94\end{array}$

If I struggle with my German homework, my parents try to find out what exactly it is that I didn't understand.

3.931 .22

When my parents help me with my homework, they always encourage me first to find the correct answers for myself. 4.11

If I don't understand something in my German classes, I can always talk about it with my parents.

Interference $(\alpha=.73)$

My parents sometimes help me with my German homework, even if I don't need any help.

1.561 .05

My parents always interfere when I'm doing my homework.

$1.77 \quad 1.14$

If I'm reading a text, my parents always interrupt me by asking questions.

1.601 .05

Usually my parents sit next to me when I'm doing my homework and tell me how my homework needs to be done.

1.651 .05 